\title{
Differential effects of testosterone, dihydrotestosterone and estradiol on carotenoid deposition in an avian sexually selected signal
}

\author{
Stefania Casagrande $\cdot$ Cor Dijkstra $\cdot$ James Tagliavini $\cdot$ \\ Vivian C. Goerlich · Ton G. G. Groothuis
}

Received: 7 June 2010 / Revised: 21 August 2010 / Accepted: 23 August 2010 / Published online: 8 September 2010

(C) The Author(s) 2010. This article is published with open access at Springerlink.com

\begin{abstract}
Recent studies have demonstrated that carotenoid-based traits are under the control of testosterone (T) by up-regulation of carotenoid carriers (lipoproteins) and/or tissue-specific uptake of carotenoids. T can be converted to dihydrotestosterone (DHT) and estradiol (E2), and variation in conversion rate may partly explain some contradictory findings in the literature. Moreover, most studies on the effect of $\mathrm{T}$ on sexual signals have focused on the male sex only, while in many species females show the same signal, albeit to a lesser extent. We studied the effects of $\mathrm{T}$, DHT, and E2 treatment in male and female diamond doves Geopelia cuneata in which both sexes have an enlarged red eye ring, which is more pronounced in males. We first showed that this periorbital ring contains very high concentration of carotenoids, of which most are lutein esters. Both $\mathrm{T}$ and DHT were effective in enhancing hue, UV-chroma and size in both sexes, while E2 was ineffective. However, E2 dramatically increased the concentration of circulating lipoproteins. We conclude that in both sexes both color and size of the secondary sexual trait are androgen dependent. The action of androgens is independent of lipoproteins regulation. Potential mechanisms and their consequences for trade-off are discussed.
\end{abstract}

Keywords Lutein · Lipoprotein · Skin · Bird · Diamond dove

S. Casagrande · C. Dijkstra · V. C. Goerlich · T. G. G. Groothuis Behavioral Biology, Centre for Behavior and Neuroscience, University of Groningen, P.O. Box 14,

9750 AA Haren, The Netherlands

S. Casagrande $(\bowtie) \cdot J$. Tagliavini

Department of Evolutionary and Functional Biology,

Parma University, V. Usberti 11/a, 43100 Parma, Italy

e-mail: casagrande@biol.unipr.it

\section{Introduction}

Colorful traits have attracted the attention of biologists since the beginning of the history of evolutionary theory (Darwin 1871) and understanding the mechanisms producing these signals is important for answering their function and evolution. Secondary sexual traits are often much more elaborated in the male sex, playing a role in mate attraction or male-male competition. The physiological processes involved in the production of such a trait are a key element in two main, but not mutually exclusive, evolutionary hypotheses proposed for explaining honest signaling about the quality of the sender (sensu Zahavi 1975). The immune competence handicap hypothesis (Folstad and Karter 1992) states that the cost of the signal, required for honest signaling, is due to the immunosuppressive effect of testosterone (T), the latter being required for signal expression. Evidence for this is ambiguous (reviewed in Roberts et al. 2004; Muehlenbein and Bribiescas 2005). The second theory (the oxidation handicap hypothesis, Alonso-Alvarez et al. 2007) proposes that $\mathrm{T}$ may impair the antioxidative barrier by increasing the level of circulating free radicals, due to increased metabolic rate and diverting carotenoids that may enhance antioxidant capacity, from the body to sexually selected traits. This would then result in oxidative stress and damage of biologically relevant molecules, such as DNA. This hypothesis is supported by a study on the zebra finch (Taeniopygia guttata), showing that the antioxidant barrier is the lowest in males implanted with testosterone (Alonso-Alvarez et al. 2007). Moreover, the finding that carotenoids can be involved in immune enhancing and antioxidant activity (Blas et al. 2006; McGraw and Ardia 2007; Alonso-Alvarez et al. 2008; Pérez-Rodríguez 2009) is also consistent with this hypothesis although evidence for a strong antioxidant activity of carotenoids is still weak, at 
least in vivo (e.g., Costantini et al. 2007; Costantini and Moller 2008).

Fleshy traits, such as the periorbital ring, supraorbital combs and wattles, are interesting for assessing the validity of sexual selection hypotheses, as they can change size and color over a short time period, signaling the current condition of the sender, in contrast to, for example, feathers or hair that change over a much longer time period. The general pattern is that the intensity of fleshy trait coloration is enhanced by androgens (e.g., Eens et al. 2000; Mougeot et al. 2007). This can be due to androgens stimulating blood flow at the tissue level, as observed in the comb and wattles of the red jungle fowl (Gallus gallus, Hardesty 1931) or in the bill and bill knock of the shelduck (Tadorna tadorna; Groothuis and Dütmann 2008), or to the regulation of pigment content in the tissue, as observed for carotenoid-based traits (Mougeot et al. 2007). The latter has received much attention in recent years as they can be considered condition-dependent traits (Johnsen et al. 2003; Peters et al. 2007) due to the trade-off between carotenoid allocation to health or signaling functions (Faivre et al. 2003; McGraw and Ardia 2003). In particular, studies on eye rings and combs clearly show that these traits honestly signal health status (Mougeot et al. 2005; Blas et al. 2006; Kristiansen et al. 2006; Martínez-Padilla et al. 2007; Mougeot et al. 2007, 2009; Mougeot 2008; Perez-Rodriguez and Vinuela 2008; Perez-Rodriguez et al. 2008) and thus can be employed for investigating them in the context of sexual selection. Carotenoids are important compounds for stimulation of the immune system and perhaps for antioxidant functions (reviewed in Olson and Owens 1998; Møller et al. 2000) but cannot be synthesized de novo by the animal itself. Therefore, they have to be taken up directly from the diet, although some of them are subsequently converted to other biologically active forms. Xanthophylls (oxycarotenoids) are the commonest avian carotenoids and they can be readily removed from fleshy traits (Casagrande and Groothuis, submitted; Faivre et al. 2003 for other bare parts), probably to be reallocated to immunological functions, or they can be degraded while acting as antioxidants, for example, after exposure to UV radiation and free radicals production as observed in the skin of mice (Lee et al. 2004).

Although carotenoid-based traits have been extensively studied (for a review see McGraw 2006a), the mechanisms involved in pigment absorption and body distribution are not well known (Kiefer et al. 2002). It is has been ascertained that carotenoids are transported in the blood by lipoproteins (Parker 1996) and that the pigments are tissue specifically acquired from these transporters (e.g., Ando and Hatano 1988; Vanhoutteghem et al. 2004). The role of androgens is, however, less clear. For example, in zebra finches $\mathrm{T}$ enhances both lipoprotein availability and beak coloration in males but only the latter in females (McGraw 2006b). Furthermore, in the red grouse (Lagopus lagopus scoticus) $\mathrm{T}$ enhances carotenoid deposition in the comb of the males but not carotenoid concentrations in the blood (Mougeot et al. 2007) while in the red-legged partridge (Alectoris rufa) T does not cause an increase in males' eye ring coloration (Blas et al. 2006), or even decreases color intensity (Alonso-Alvarez et al. 2008). In addition, in the red-legged partridge it has been shown that $\mathrm{T}$ can enhance eye ring coloration and circulating carotenoids in middle age males, while having no effect in old individuals (Alonso-Alvarez et al. 2009). None of these studies investigated the potential role of T-metabolites and their potentially differential effect on coloration or lipoproteins status. $\mathrm{T}$ can be converted to dihydrotestosterone (DHT) and estradiol (E2), with both T and DHT binding to the same receptor (Roya et al. 1998) in target tissues and only the latter to estradiol receptors (Levin 2005). DHT cannot be converted to E2 and has a higher affinity to the androgen receptor than T. Knowing which sex steroid is involved in trait regulation can be crucial in the context of sexual selection investigation as androgens and estrogens can have opposite effects on the immune system (Grossman 1985; Olsen and Kovacs 1996) as well as on lipoprotein availability (Kudzma et al. 1973; Luskey et al. 1974). In addition, it has recently been proposed that the honesty of carotenoid-based signals is based on the cost of up-regulating carotenoid carriers, the lipoproteins (McGraw and Parker 2006) and that T administration increases lipoprotein concentration in the blood (McGraw et al. 2006). Therefore knowledge of the different roles of the different steroids can increase our understanding of the potential cost of carotenoid-dependent signaling.

Another gap in the experimental study of carotenoidbased fleshy signals is the investigation of female signaling (but see Eens et al. 2000). Especially in monogamous species females possess similar signals as males, although often less elaborated. In such species males, like females, may select their partners too on the basis of such signals. Moreover, in case the hormonal mechanism underlying male and female signaling is the same, the consequences for one sex may constrain the evolution in the other sex (Ketterson et al. 2005; McGlothlin and Ketterson 2008).

The present study was carried out to investigate the relationship between T, DHT and E2 on the one hand and carotenoid-dependent bare skin coloration and circulating lipoproteins in both males and females diamond dove Geopelia cuneata on the other. The diamond dove is a small ( $\sim 35 \mathrm{~g})$ seed eating columbid species, adapted to extremely arid environments of Australia, breeding opportunistically in accordance with trophic conditions (Schleucher et al. 1991). It is socially monogamous and incubation, brooding and young feeding are equally shared between parents. Diamond doves have a relative extensive 
red-orange periorbital ring of bare skin. Males have, especially in the reproductive season, bigger and more intense coloration of the periorbital ring than females (Gray 1970; Voets 1980; this paper). We first established the high carotenoid level in the eye ring and characterized its carotenoids as well as the carotenoids in the food provided to the birds during the experiment to ascertain if carotenoids deposited in the trait have been metabolically transformed after their absorption in the gut. Next, we experimentally manipulated steroid hormone levels and determined their effect on plasma concentrations of hormones, lipoproteins and eye ring color in both sexes.

\section{Materials and methods}

Housing condition

We used 96 birds, housed in individual male-female pairs in indoor cages at the Biology Department of the RUG University, in a room set at constant short photoperiod (8L:16D) at about $20^{\circ} \mathrm{C}$. The short photoperiod started 4 weeks before the experiment and was aimed to prevent the non-castrated birds to become sexually active, thereby maintaining a low level of endogenous steroids. Pairwise housing was used to provide a normal social condition since isolated birds showed clear signs of distress. Pairs only had auditory but not visual contact with other pairs. They were supplied with food (tropical seed mix) and water ab libitum and acclimatized to the pair-housing condition for 1 week before the start (day 0 ) of the experiment. The sex of each bird was molecularly determined following Fridolfsson and Ellegren (1999).

\section{Design}

At day 0 birds were randomly assigned to one of the four steroid treatments: testosterone (T), $5 \alpha$-dihydrotestosterone (D), 17- $\beta$-estradiol (E) and control (C). Each experimental group consisted of 12 males and 12 females. To reach a balanced condition of housing related to hormone treatment, sex, and pairing, we re-allocated the birds over all the possible pair combinations, obtaining three cages per each of the following combination (small letter is referred to sex and capital to hormone treatment): mT-fT, mT-fD, mT-fE, mT-fC, mE-fD, mE-fT, mE-fE, mE-fC, mC-fC, mC-fE, mC-fD, mC-fT, mD-fC, mDHT-fE, mDHT-fD, mD-fT. Three individuals were erroneously sexed. This was ascertained after the end of the experiment, when birds were exposed to long daylight photoperiod and showed sex-specific courtship behavior. DNA analysis was then re-performed for wrong sexed birds only and molecular sexing matched behavioral sexing. Thus, there was one cage with
$2 \mathrm{C}$ males, 1 with $2 \mathrm{C}$ females and one with $2 \mathrm{~T}$ females. Since this housing condition did not affect their hormonal status compared with the other birds, and the results concerning our dependent variables were similar when these birds were either included or excluded from the analyses, we decided to include all birds in the statistical analysis to increase statistical power.

At day 0 (starting the hormone treatment, see below) and day 14 we took measurements of color and size of the eye ring as well as of body mass (see below) of all birds. At day 20 we took blood samples to determine the effectiveness of the hormone implants and blood levels of lipoproteins and carotenoids. Since half of the birds of each hormone treatment participated in an additional experiment where birds were immuno-challenged on day 14 , which turned out to influence their hormone levels (Casagrande and Groothuis, submitted), hormone levels on day 20 could only be used from the other half of the birds for the current experiment. Since birds allocated to the immunization experiment were randomly chosen, the cohort we used should give a reliable indication for the whole batch. Due to the volume of blood required for the analyses $(450 \mu \mathrm{L})$ we could only collect blood once over the experimental period and decided to do this on day 20 since blood sampling was required on that day for the additional experiment. Therefore, we correlate eye ring measurements at day 14 with blood plasma parameters at day 20. We are confident that the blood levels of hormones at day 20 closely resemble those at day 14 , since the implants release stable levels of hormones during that time (Wingfield et al. 1984; Ketterson et al. 1991). In addition, eye ring parameters of those birds that could be measured both on day 14 and day 20, did not change significantly (paired $t$ test: size: $t_{(1,46)}=0.61, p=0.54$; hue, $t_{(1,46)}=0.79, \quad p=0.43$, UV-hue, $t_{(1,46)}=0.49, \quad p=0.49$; chroma, $t_{(1,46)}=0.77, p=0.45$; UV-chroma, $t_{(1,46)}=0.79$, $p=0.43$ ).

We also took small biopsies from the eye ring of two birds for characterization of carotenoids by HPLC. These pilot measurements were carried out on birds not included in the experimental sample. In addition, we performed this characterization on seeds provided to the birds in order to determine which carotenoids and to what extent were taken up from the food or produced endogenously.

\section{Hormone implants}

Birds were implanted on day 0 with a silicon capsule (i.d. $=1.50 \mathrm{~mm}, \quad$ o.d. $=2.0 \mathrm{~mm}$, length $=12 \mathrm{~mm}$ ) filled, with either crystalline testosterone ( $\mathrm{T}$, product number T1500), $17 \beta$-estradiol (E2, product number E2758) or $5 \alpha$ dihydrotestosterone (DHT, product number 10300) (all from Sigma-Aldrich, St. Louis). Filled tubes had been embedded for $24 \mathrm{~h}$ into phosphate buffered saline before 
implantation. Controls were implanted with empty tubes of the same size. The dimension of the implants was chosen based on earlier studies with similar-sized birds reporting a physiological increase of steroids after manipulation (Soma et al. 2000; Tramontin et al. 2003). Birds were locally anesthetized with lidocaine (Xylocaine, AstraZeneca BV, Zoetermeer) and the implant was inserted under the skin, after making a small cut in the right flank. The cut was sealed with surgical glue (Hansaplast-Beiersdforf, Hamburg).

Color and morphological measurements

The color of the sexual trait was assessed indoor in constant temperature conditions by measuring the reflectance of the eye ring every $0.35 \mathrm{~nm}$ using a portable spectrometer USB2000 (configured range $250-850 \mathrm{~nm}$ ), a light source deuterium-halogen DH-2000 (both Avantes, Erbeeck), and the software AvaSoft 5.0 (Avantes, Erbeeck). The probe, which holds both illuminating and recording optical fibers, was held at right angle against the skin. After calibration with dark and white references (WS-2, Avantes) we took three reflectance scans per each bird in a fixed location (the right side of the right eye ring), removing and replacing the probe between each scan. From raw spectral data we computed the indices of hue, chroma, UV-hue and UV-chroma from each spectral data and we considered the mean value of the three repeated scans for statistical analyses after checking for repeatability (intraclass correlation coefficients, $r_{\text {hue }}=0.80, r_{\text {chroma }}=0.86 ; r_{\mathrm{UV} \text {-hue }}=0.89 ; r_{\mathrm{UV} \text {-chroma }}=$ 0.92; all $p<0.001$; Lessels and Boag 1987). We considered the spectral range between 300 and $700 \mathrm{~nm}$, both because it is the commonest range used by birds also sensitive to UV (Hart and Vorobyev 2005) and because carotenoid-based colorations show a bimodal pattern of reflectance within this range with a first one in the UV and a second one in the yellow-red area, depending on pigments (Montgomerie 2006; our data). To describe the hue and saturation we split the total spectrum in UV spectrum (300-400) and visible spectrum (400-700) (Montgomerie 2006) and we computed the colorimetric variables of hue, UV-hue, chroma and UV-chroma as follows. Hue and UV-hue were measured as the spectral location of the midpoint between the minimum and the maximum value of the reflectance observed between 400 and $700 \mathrm{~nm}$ for hue and between 300 and $400 \mathrm{~nm}$ for UV-hue ( $\lambda_{\text {(Rmid) }}$, Andersson et al. 2002; Montgomerie 2006). We calculated chroma and UV-Croma as $R_{\max }-R_{\min } / R_{\text {average }}$, respectively, between 400 and $700 \mathrm{~nm}$ and between 300 and $400 \mathrm{~nm}$ (Andersson and Prager 2006).

The length and the width of the periorbital ring and the skull length were measured using a caliper to the nearest $0.1 \mathrm{~mm}$. An estimate of the total eye ring area was calcu- lated as an ellipse surface ( $\pi a b$, where $\pi$ is the mathematical constant and $a$ and $b$ are, respectively, the semi-major and the semi-minor axes of the ellipse) considering the two axes, respectively, the longer and shorter axis of the ring. The area of the eye, calculated for 10 individuals ( 5 males and 5 females) was subtracted from the periorbital area and was calculated as a circle area from a mean diameter of $4.35 \pm 0.07 \mathrm{~mm}$.

Body mass was measured with a digital balance to the nearest $1 \mathrm{~g}$ and an index of body condition (BC) was calculated as the residuals of a linear regression of body mass on skull length (Chastel et al. 2005) $\left[F_{(1,189)}=58.09, p<\right.$ $\left.0.0001, R^{2}=0.24\right)$. No differences in secondary sexual trait expression (color and size) and body condition were observed between hormone treatment groups before the starting of the experiment (hue: $F_{(3,92)}=1.63, p=0.19$; UV-hue: $F_{(3,92)}=1.01, p=0.30$; chroma: $F_{(3,92)}=0.79, p=0.50$; UV-chroma: $F_{(3,92)}=1.46, p=0.23$; size: $F_{(3,92)}=0.44$, $p=0.73$; $\left.\mathrm{BC}: F_{(3,92)}=0.11, p=0.35\right)$.

\section{Blood sampling}

Blood (350-450 $\mu \mathrm{L})$ was sampled from the wing vein with a heparinized syringe, kept on ice for maximum $5 \mathrm{~h}$ until centrifugation at $14,000 \mathrm{rpm}$ for $5 \mathrm{~min}$ to separate the plasma. Both plasma and precipitated part was frozen at $-20^{\circ} \mathrm{C}$ until analysis. Although it should be useful to have starting value of hematological parameters, we avoided repeated bleeding that could interfere with carotenoids allocation and general condition of the bird.

Steroid radioimmunoassay (RIA)

To determine plasma concentrations of the three gonadal hormones, plasma samples were extracted twice adding to the weighed plasma $(150-200 \mu \mathrm{L}) 4 \mathrm{~mL}$ of petroleum ether/diethylether (30-70\%) allowing steroids to pass from the watery phase to the organic one. The extraction was dried under a nitrogen stream and then dissolved in $90 \%$ ethanol, dried again under nitrogen stream, dissolved in $70 \%$ methanol and placed at $-20^{\circ} \mathrm{C}$ overnight. The solution was dried and dissolved in $185 \mu \mathrm{L}$ of PBSG-buffer. T was assayed from $50 \mu \mathrm{L}$ of plasma, using DSL-4000 Active Testosterone Coated-Tube Radio immunoassay Kit (Diagnostic System Laboratories, Inc., Webster). DHT was assayed from $25 \mu \mathrm{L}$ of plasma using DSL-96100 Dihydrotestosterone Radio immunoassay Kit (Diagnostic System Laboratories, Inc., Webster) following the protocol provided with the kit. Estradiol was assayed in $50 \mu \mathrm{L}$ of plasma using DSL-4400 Estradiol Radioimmunoassay Kit (Diagnostic System Laboratories, Inc., Webster) following the protocol of the kit. The concentrations of steroids are expressed in picograms per milliliter. Twenty microliters of 
the extract was used to assess extraction efficiency by counting the amount of radioactivity recovered. The intraand inter-assay coefficient of variation $(\mathrm{CV})$ were, respectively, DHT, $1.57 \pm 0.16$ and $6.66 \pm 0.88 \%$; E2, $4.96 \pm 1.11$ and $6.30 \pm 0.95 \% ; \quad T, 4.13 \pm 1.17$ and $15.39 \pm 1.28 \%$, while average recovery was $83 \%$. Crossreactivity with steroids other than the target was low (testosterone antibody: $5.8 \%$ with $5 \alpha$-dihydrotestosterone, $2.3 \%$ with androstenedione, $0 \%$ with estrogens; $5 \alpha$-dihydrotestosterone antibody: androstandiol 3.3\%, testosterone $0.6 \%$, $0 \%$ with estrogens; $17 \beta$-estradiol antibody: $3.40 \%$ with estrone and $0 \%$ with androgens).

\section{Carotenoid analysis}

A semi-quantitative analysis was conducted to ascertain if the coloration of the periorbital eye ring was produced by carotenoids. The eye ring of two reproductively active birds (a male and a female not belonging to the experimental sample) were anesthetized with lidocaine and a skin sample of about $2.5 \mathrm{~mm}^{2}$ was excised and stored in ethanol until high performance liquid chromatography (HPLC). The plasma $(100 \mu \mathrm{L})$ of 10 non-experimental reproductively active birds ( 5 males and 5 females) was also analyzed with HPLC in order to compare circulating and eye ring stored carotenoid. We performed a HPLC analysis also on the tropical seed mix to evaluate the quality and quantity of carotenoids available in the food offered to the birds. HPLC analyses were carried out in the Department of Organic Chemistry of the University of Milan (cf., Stradi et al. 1995 and Casagrande et al. 2006 for a detailed description of the method). Briefly, carotenoids were extracted from a weighed amount of skin, plasma or seeds with the same protocol used for the other organic complex matrix, as described in Schiedt et al. (1995) and Saino et al. (2002) for egg yolk analysis. The chromatographic analyses were prolonged to $75 \mathrm{~min}$ to evaluate the presence of esters. Pigments detected in the skin were identified by the retention time, the UV spectra and from LC/MS-MS analysis. Seeds pigments were identified by retention time, UV spectra and co-chromatography with standards. No pigments were detected in the plasma.

To measure the amount of carotenoids circulating in the blood, the plasma $(20 \mu \mathrm{L})$ was diluted with absolute methanol $(1: 25)$ and the flocculent proteins were precipitated by centrifugation at $12,000 \mathrm{rpm}$ for $5 \mathrm{~min}$. Carotenoids were quantified with a Pharmacia Biotech Ultrospec (Pharmacia, Cambridge) spectrophotometer at $445 \mathrm{~nm}$. The carotenoid concentration was estimated as $\mu \mathrm{g} \mathrm{mL}^{-1}$ of serum using the standard absorbance curve of lutein (Sigma-Aldrich product number 95507). HPLC of blood samples could not detect any carotenoids and the quantitative analyses of the blood sampled from experimental birds failed, again, in detecting any carotenoid circulating in the blood. Since these pigments
Table 1 Results of HPLC analyses of eye ring skin biopsy of a male and a female diamond dove and of food provided during the study

\begin{tabular}{lccl}
\hline Compound & $\begin{array}{l}\text { Female skin } \\
\left(\mu \mathrm{g} \mathrm{g}^{-1}\right)\end{array}$ & $\begin{array}{l}\text { Male skin } \\
\left(\mu \mathrm{g} \mathrm{g}^{-1}\right)\end{array}$ & $\begin{array}{l}\text { Seeds } \\
\left(\mu \mathrm{g} \mathrm{g}^{-1}\right)\end{array}$ \\
\hline Dehydrolutein & 6.17 & 45.51 & nd \\
Trans-Lutein & 8.99 & 28.92 & 2.51 \\
Cis-Lutein & 2.15 & 49.20 & nd \\
Zeaxanthin & 4.68 & 76.38 & 0.24 \\
Lutein ester 1 & 159.87 & 554.88 & nd \\
Lutein ester 2 & 78.13 & 264.30 & nd \\
Lutein ester 3 & 51.14 & 255.10 & nd \\
Total carotenoids & 311.13 & $1,274.29$ & 2.75 \\
\hline
\end{tabular}

$n d$ not detected

were detected in the skin in a relative high concentration (Table 1), we supposed that the diamond doves are highly efficient in allocating carotenoids to specific tissues, maintaining their blood concentrations at very low levels, not detectable with the used devises. In addition, blood levels of carotenoids could be elevated only at the time of an increase in deposition or reallocation, while we have measured them in a stable situation. We do not think that this was an artifact, for example, sample degradation is an unlikely explanation because all other blood parameters from the same blood samples yielded values that are comparable with data in the literature. Additional analyses with HPLC using different birds and solvents gave the same results.

Cholesterol analysis

To evaluate the concentration of carotenoid carriers (lipoproteins) in the peripheral blood, we measured the total amount of cholesterol, which is an important component of lipoproteins in animals and that has been used as proxy of lipoproteins in birds (McGraw and Parker 2006). We diluted $10 \mu \mathrm{L}$ of plasma with $1 \mathrm{~mL}$ of the reagent kit Nobiflow Cholesterin (Hitado Diagnostic System, Möhnesee-Delecke) reading the sample with the spectrophotometer Pharmacia Biotech Ultrospec (Pharmacia, Cambridge) at $500 \mathrm{~nm}$. The concentration of cholesterol was calculated in milligrams per deciliter referring to Nobical Cholesterin (Hitado Diagnostic System, Möhnesee-Delecke) as standard. The kit is sensitive to both LDL-cholesterol (low density lipoproteins) and HDL-cholesterol (high density lipoproteins).

Data analysis

All analyses were performed with STATISTICA 7.0 (StatSoft 2004, Tulsa, OK, USA). A GLM ANCOVA was performed for each eye ring variable (color variables and size) and for body condition index, considering sex and hormone 

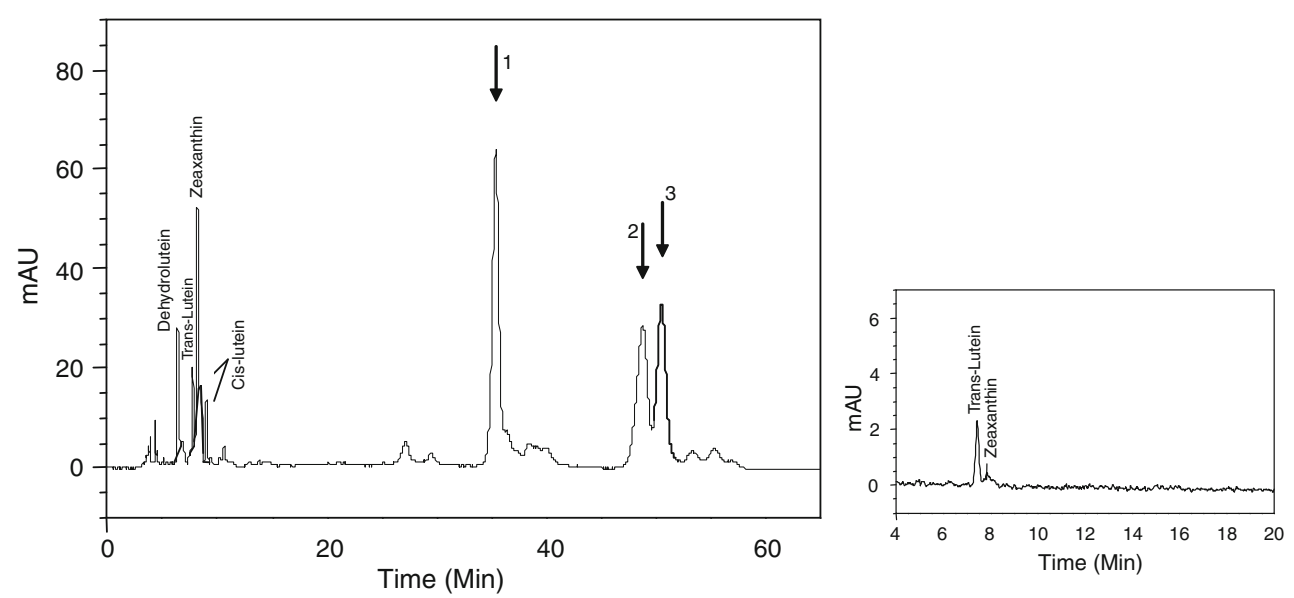

Fig. 1 Representative chromatograms from HPLC analysis of periorbital skin (larger right panel) and tropical mix seeds (smaller left panel). Arrows indicate lutein esters 1,2 and 3

treatment as fixed factors and as covariate the value of the corresponding variable registered on day 0 . The latter was included to correct for variation in initial values since we are interested in the change in these variables due to hormone treatment. Since body mass or size may influence ring size we added these first two as covariates in the model analyzing eye ring variables but since their explanatory value was minimal and far from statistical significance we removed them from all models. A GLM ANOVA was performed for considering, respectively, steroid levels and cholesterol as dependent variables, and sex and hormone treatment as fixed factors. Interactions and factors were sequentially removed from the models when non-significant $(p>0.05)$ following a standard backward procedure. We report values from non-significant predictors removed from the full model and those for significant ones from the final model. Normality was tested with Kolmogorov-Smirnoff and steroids levels were log transformed as they did not reach the normal distribution. Data are reported as mean \pm SE. We performed post hoc tests for detecting which hormone treatment differed from each other when the overall effect of treatment was significant $(p<0.05)$. We performed post hoc tests detecting within which hormone treatment there was an effect of sex only when the interaction between sex and hormone treatment was significant, except for one case in which the data indicated lack of power for such an interaction. Post hoc tests were performed by using Fisher LSD tests after removing non-significant factors.

\section{Results}

\section{Carotenoid characterization}

The bare skin of the two periorbital rings contained a high concentration of xanthophylls (dehydrolutein, lutein, zeaxanthin, and lutein esters; Fig. 1) with the ones of the males having higher levels than the ones of the females (Table 1). Trans-lutein and zeaxanthin, being present in the seeds, may have been acquired by the bird from the diet and deposited in tissues without any transformation, in contrast to $c i s$-lutein and dehydrolutein which were lacking in the food. It is known that dehydrolutein can be converted from zeaxanthin and/or cis- and trans-lutein by oxidation (Gesa et al. 2008). The skin also contained high concentrations of lutein esters (Table 1; Fig. 1). The latter represented $92 \%$ of the female and $84 \%$ of the male total skin carotenoids, respectively, while these esters were not detected in the food provided.

Effect of hormone treatment on plasma concentrations of steroids and cholesterol

DHT treatment, irrespectively of sex, influenced DHT plasma concentrations (Table 2a). Post hoc tests revealed, as expected, that DHT was elevated not only in the DHTtreated birds but also in the T-treated birds, since $\mathrm{T}$ can be converted to DHT and this was the case in both sexes (Fig. 2a).

Again as expected, $\mathrm{T}$ increased only in the $\mathrm{T}$ group, both in males and in females, with males showing higher levels than females (Fig. 2b). Indeed, there were significant effects of hormone treatment and sex on $\mathrm{T}$ levels. Although the figure shows that this sex difference is lacking in the Ttreatment group there was no significant interaction effect between sex and treatment (Table $2 b$ ).

Treatment also significantly affected E2 levels irrespectively of sex (Table 2c). Post hoc tests revealed that E2 was suppressed in the $\mathrm{T}$ group and showed a similar tendency in the DHT group (Fig. 2c), likely by affecting the negative feedback on the HPG axis (Roselli and Resko 1993), and indicating low levels of aromatase activity. Surprisingly, 
Table 2 Results of statistical tests explaining variation of steroid concentrations in peripheral blood plasma with hormone treatment and sex as predictors

\begin{tabular}{|c|c|c|c|c|}
\hline \multirow[t]{2}{*}{ Variables and factors } & \multicolumn{2}{|c|}{ Original model } & \multicolumn{2}{|c|}{ Final model } \\
\hline & $d f \quad F$ & $p$ & $d f \quad F$ & $p$ \\
\hline
\end{tabular}

(a) Dihydrotestosterone

$\begin{array}{lrrcccc}\text { Sex (S) } & 1 & 2.48 & 0.12 & & & \\ \text { Treatment (Tr) } & 3 & 22.13 & <0.0001 & 3 & 22.31 & <0.0001 \\ \mathrm{~S} \times \operatorname{Tr} & 3 & 1.14 & 0.34 & & & \\ \text { Error } & 39 & & & & 43 & \\ \text { (b) Testosterone } & & & & & & \\ \text { Sex } & 1 & 4.74 & 0.04 & 1 & 4.67 & 0.04 \\ \text { Treatment } & 3 & 16.87 & <0.0001 & 3 & 18.01 & <0.0001 \\ \mathrm{~S} \times \operatorname{Tr} & 3 & 1.18 & 0.33 & & & \\ \text { Error } & 39 & & & & 42 & \end{array}$

(c) Estradiol

$\begin{array}{lrccccc}\text { Sex } & 1 & 0.46 & 0.50 & & & \\ \text { Treatment } & 3 & 6.75 & <0.001 & 3 & 6.37 & <0.001 \\ \mathrm{~S} \times \operatorname{Tr} & 3 & 1.08 & 0.37 & & & \\ \text { Error } & 39 & & & 43 & \end{array}$

(a) DHT, (b) T, (c) E2

E2 treatment did not enhance E2 levels above those of controls. However, Fig. 2c suggests that this is caused by the fact that control females have already elevated E2 levels, as would be expected by reproductively active females. Indeed, post hoc tests revealed that E2 levels in E2-treated males were higher than those of control males (LSD post hoc, $p=0.05$ ) but not in control females (LSD post hoc, $p=0.91)$. For non-transformed data of all hormone values see Appendix, Table 4. Cholesterol increased only in E2treated birds (GLM ANOVA final model, steroid treatment: $F_{(3,43)}=11.74 ; p<0.0001$, Fig. 3) independently of sex or the interaction between sex and treatment (full model: sex: $F_{(1,39)}=0.30, p=0.58 ;$ sex $\times$ steroid treatment: $F_{(3,39)}=$ $1.22, p=0.31)$.

Effect of steroid treatment on color and size of the eye ring and on body condition

Hue was strongly affected by hormone treatment (Table 3a) as $\mathrm{T}$ and $\mathrm{D}$ birds increased hue values compared to $\mathrm{C}$, while $\mathrm{E}$ birds decreased it (Fig. 4a). The interaction between sex and hormone treatment and sex alone were not significant in the full model and therefore removed from the final model (Table 3a). UV-hue was affected by hormone treatment (Table 3b) as E birds showed higher values than C (Fig. 4b). Sex and its interaction with hormone treatment was not significant (Table 3b). Chroma variation was explained by the interaction between sex and hormone treatment (Table 3c), with $\mathrm{T}$ and $\mathrm{D}$ males showing higher values of chroma than $\mathrm{T}$
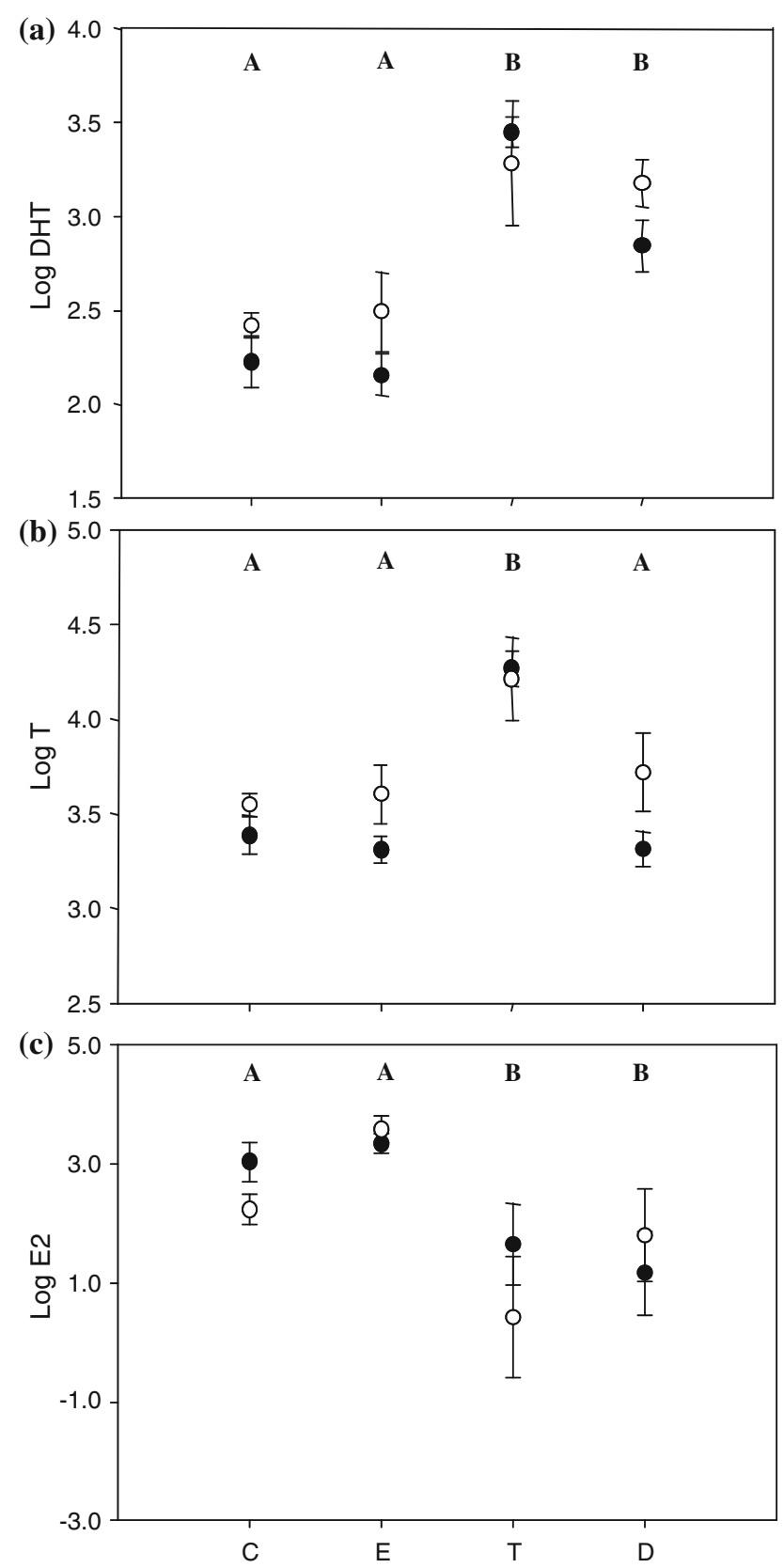

Fig. 2 Log steroids concentration (averages and SE in $\mathrm{pg} \mathrm{mL}^{-1}$ ) measured on day 20 for 47 birds belonging to 4 steroid treatments $(C, E$, $T$ and $D)$. Letters refer to significant differences between hormone treatment groups $(p<0.05)$ (filled circle female, empty circle male)

and D females (Fig. 4c). UV-chroma was strongly affected by hormone treatment (Table 3d) as T and D birds increased UV-chroma compared to C (Fig. 4d) independently of sex or its interaction (Table 3d).

Treatment significantly affected eye ring size as revealed by the significant effect of treatment (final model: $\left.F_{(1,90)}=8.32, p<0.0001\right)$ in the GLM ANCOVA model (size day-0: $F_{(1,90)}=32.82, p<0.0001$, Fig. 5). Post hoc analyses showed that size increased in birds treated with $\mathrm{T}$ 
Table 3 Results of statistical tests explaining variation of colorimetric variables of periorbital ring with hormone treatment and sex as predictors and variables measured on day 0 as covariate

\begin{tabular}{|c|c|c|c|c|c|c|}
\hline & \multicolumn{3}{|c|}{ Original model } & \multicolumn{3}{|c|}{ Final model } \\
\hline & $d f$ & $F$ & $p$ & $d f$ & $F$ & $p$ \\
\hline \multicolumn{7}{|l|}{ (a) Hue } \\
\hline $\operatorname{Sex}(\mathrm{S})$ & 1 & 3.47 & 0.07 & & & \\
\hline Treatment (Tr) & 3 & 13.85 & $<0.0001$ & 3 & 13.53 & $<0.0001$ \\
\hline $\mathrm{S} \times \operatorname{Tr}$ & 3 & 0.33 & 0.80 & & & \\
\hline Hue day-0 & 1 & 61.10 & $<0.0001$ & 1 & 68.03 & $<0.0001$ \\
\hline Error & 87 & & & 91 & & \\
\hline \multicolumn{7}{|l|}{ (b) UV-hue } \\
\hline Sex & 1 & 0.24 & 0.63 & & & \\
\hline Treatment & 3 & 3.99 & 0.01 & 3 & 4.02 & 0.01 \\
\hline $\mathrm{S} \times \operatorname{Tr}$ & 3 & 2.11 & 0.10 & & & \\
\hline UV-hue day-0 & 1 & 13.46 & $<0.001$ & 1 & 15.92 & 0.0001 \\
\hline Error & 87 & & & 91 & & \\
\hline \multicolumn{7}{|l|}{ (c) Chroma } \\
\hline Sex & 1 & 6.62 & 0.01 & & & \\
\hline Treatment & 3 & 3.74 & 0.01 & & & \\
\hline $\mathrm{S} \times \operatorname{Tr}$ & 3 & 4.06 & $<0.01$ & & & \\
\hline Chroma day-0 & 1 & 8.66 & $<0.01$ & & & \\
\hline Error & 87 & & & & & \\
\hline \multicolumn{7}{|l|}{ (d) UV-chroma } \\
\hline Sex & 1 & 0.04 & 0.83 & & & \\
\hline Treatment & 3 & 7.75 & 0.0001 & 3 & 7.56 & 0.0001 \\
\hline $\mathrm{S} \times \operatorname{Tr}$ & 3 & 1.73 & 0.17 & & & \\
\hline UV-chroma day-0 & 1 & 15.00 & $<0.001$ & 1 & 18.21 & $<0.0001$ \\
\hline Error & 87 & & & 91 & & \\
\hline
\end{tabular}

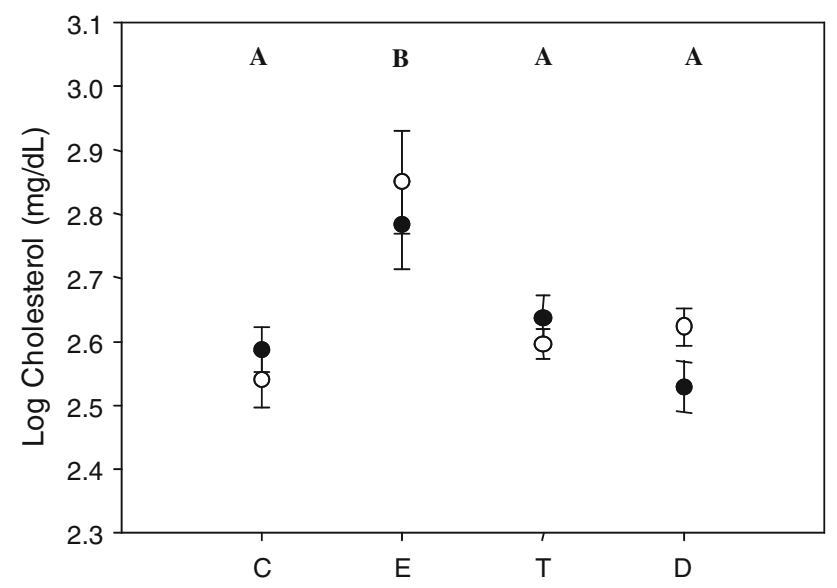

Fig. 3 Mean values \pm SE of cholesterol concentration measured on day 20 of 47 birds. See legend of Fig. 2

or DHT, both in males and females. The model showed also an effect of sex (final model: $F_{(1,90)}=15.90, p<0.0001$ ) with a greater eye ring for males in all treatments groups
(Fig. 5), while the interaction between sex and hormone treatment was removed from the original model because not significant (GLM ANCOVA sex $\times$ hormone treatment: $\left.F_{(1,87)}=0.09, p=0.97\right)$. We considered sex differences in periorbital ring of control birds to evaluate if this trait can be considered sexually dimorphic. We found a significant difference only for size of the eye ring (female: $23.50 \pm 2.10 \mathrm{~mm}^{2} ;$ male: $32.50 \pm 1.93 \mathrm{~mm}^{2} ;$ one-way ANOVA: $\left.F_{(1,22)}=9.95, p=0.004\right)$ while the differences in color parameters did not reach statistical significance, perhaps because the birds were sexually inactive (hue: female: $579 \pm 3.89 \mathrm{~nm}$, male: $589 \pm 3.58 \mathrm{~nm}$; one-way ANOVA: $F_{(1,22)}=2.97, p=0.10$; UV-hue: female: $318 \pm 0.56 \mathrm{~nm}$, male: $317 \pm 0.51 \mathrm{~nm}$; one-way ANOVA: $F_{(1,22)}=0.40$, $p=0.55$; chroma: female: $1.64 \pm 0.13$, male: $1.75 \pm 0.12$; one-way ANOVA: $F_{(1,22)}=0.43, p=0.52$; UV-chroma: female: $0.56 \pm 0.03$, male: $0.54 \pm 0.02 \mathrm{~nm}$; one-way ANOVA: $\left.F_{(1,22)}=0.58, p=0.45\right)$.

Only sex explained BC variation (GLM ANCOVA final model: sex, $F_{(1,93)}=4.91, p=0.03$; $\mathrm{BC}$ day- $0: F_{(1,93)}=8.39$, $p=0.005$ ) while hormone treatment and sex $\times$ hormone treatment were removed (original model: hormone treatment, $F_{(3,87)}=1.88, p=0.14$, sex $\times$ hormone treatment, $F_{(3,87)}=$ $1.42, p=0.24$; Fig. 6 ).

\section{Discussion \\ Characterization of skin carotenoids}

In order to better understand the hormonal control of sex differences in carotenoid-dependent sexual signals we treated male and female diamond doves with the aromatizable testosterone, the non-aromatizable dihydrotestosterone and estradiol, after first characterizing carotenoids in the signal, the red enlarged eye ring.

By analyzing carotenoid content of the food we provided to the birds we demonstrate that only two (zeaxanthin and trans-lutein) out of the seven carotenoids we detected in the skin were present in the food too, indicating that the birds substantially metabolize these two compounds. In particular, this is one of the few studies that have detected dehydrolutein, an oxidized form of lutein and zeaxanthin (Gesa et al. 2008), in the integument of birds (Costantini et al. 2009). Interestingly, the eye ring contains very high amounts of carotenoid esters. Carotenoid esters have been previously found in the skin of the legs of the domestic goose (Anser anser domestica), in the skin of comb and leg of the domestic hen (Gallus gallus domesticus), in the wattle of the turkey (Meleagris gallopavo) and in the bare skin of the partridge (Perdix perdix) (Czeczuga 1978). In all the reported cases only astaxanthin esters have been detected while we found mainly lutein esters. Moreover, the levels 

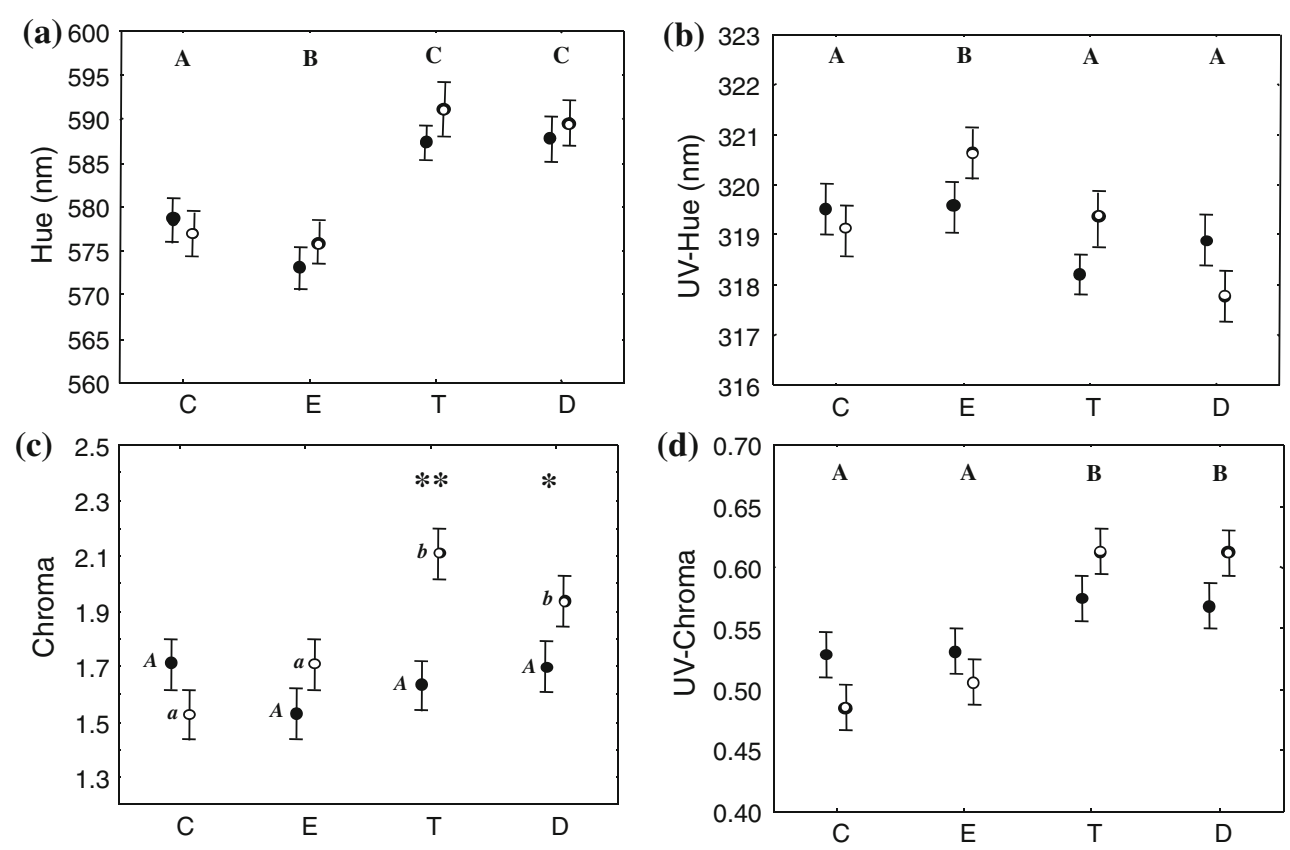

Fig. 4 Effects of steroid treatments $(C, E, T$ and $D)$ and sex (filled circle female, empty circle male) on eye ring colorimetric variables on day 14; corrected for their initial values. a Hue outside the UV range, b hue in the UV range, $\mathbf{c}$ chroma outside the UV range, $\mathbf{d}$ chroma in the UV range. Capital letters above data refer to significant differences

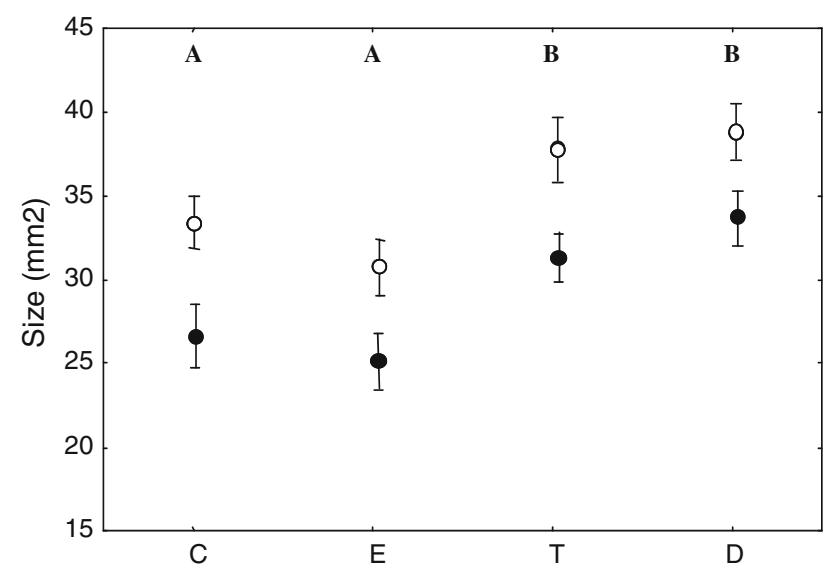

Fig. 5 Effects of steroid treatments $(C, E, T$ and $D$ ) and sex (filled circle female, empty circle male) on eye ring size measured on day 14 and corrected for initial value. See legend of Fig. 2

reported in the literature are much lower (total carotenoid content of the leg of domestic birds: $0.396-0.846 \mu \mathrm{g} \mathrm{g}^{-1}$; wattle of turkey: $1.954 \mu \mathrm{g} \mathrm{g}^{-1}$; Czeczuga 1978) compared to the amount of carotenoids that we found in the periorbital ring of the diamond dove $\left(311.12 \mu \mathrm{g} \mathrm{g}^{-1}\right.$ for female and $1,274.29 \mu \mathrm{g} \mathrm{g}^{-1}$ for male).

Lutein is transported by lipoproteins in the free form (Tyczkowski and Hamilton 1986) and lutein esters are remobilized from the integument also in the free form, after specific enzymatic steps (Schaeffer et al. 1988). Therefore

between hormone treatment groups $(p<0.05)$. Since sex and its interaction with treatment were significant in explaining chroma variation, c reports post hoc between hormone treatments within sex (capital letters for males and lowercase for females; $p<0.05$ ) and post hoc between sex within hormone treatment $(* * p<0.01 ; * p<0.05)$

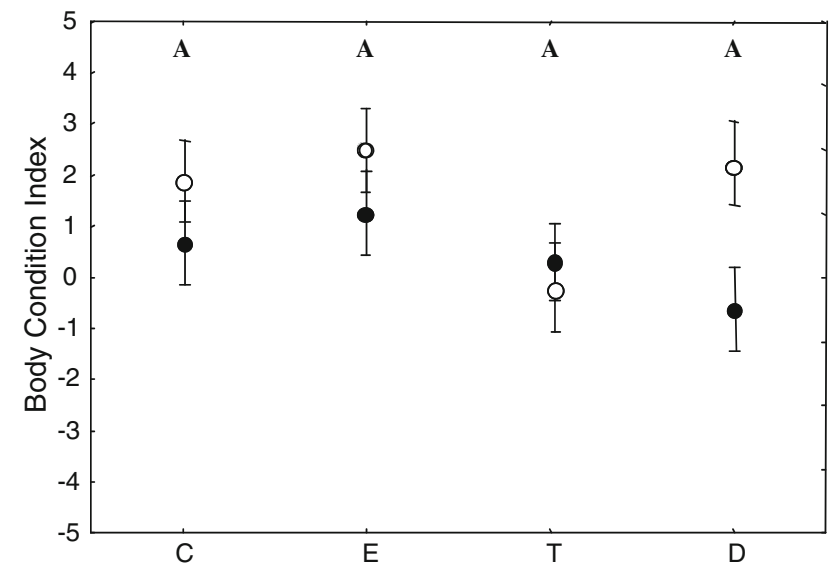

Fig. 6 Body condition index of 96 birds measured on day 14 (corrected for initial value) reported per steroid treatments $(C, E, D$ and $T)$ and sex (filled circle female, empty circle male). See legend of Fig. 2

our findings suggest the expression in situ of specific enzymes responsible of the esterification, as observed in the toe web of chickens, one of birds' major sites of lutein esters deposition (Tyczkowski and Hamilton 1986). The high levels detected in the periorbital ring of the diamond dove indicate that it is specialized to absorb and store carotenoids and perhaps this may be an adaptation of the diamond dove to the high temperature in their habitat since esterified carotenoids are more stable if exposed to high temperature or UV radiation than free carotenoids (Subagio 
et al. 1999), while maintaining the typical spectra property of xanthophylls (Pintea et al. 2005).

\section{Effectiveness of hormone treatments}

Both T and DHT treatments were effective in increasing peripheral concentrations of the steroid of interest, independently of sex. T increased DHT too, since the former can be readily converted to the latter in a variety of tissues (Pirog and Collins 1999; Gingras et al. 2003). E2 was elevated only in males receiving E2 treatment and not in females, because control females showed high levels of E2 already. We are confident that E2 treatment worked because of its effect in inducing hypercholesterolemia (Chapman 1980; Dashti et al. 1983) in both sexes. In addition, E2 suppressed androgen production, most likely via its effect on the HPG axis.

We do not have data for the natural range of these steroid levels in reproductively active diamond doves not treated with the hormones and housed under normal light dark schedule (we housed them under short L-D cycle) but there are data available for similar-sized bird species. Only the values of $\mathrm{T}$ in our T-treated birds and perhaps E2 in E2treated males (Table 3) seem quite high. However, it is not uncommon to find such high concentration in un-manipulated birds (for a discussion on a comparable bird species, the zebra finch, see Alonso-Alvarez et al. 2007). Moreover, pharmacologically detrimental levels are expected to affect general conditions, but we have not found any detrimental effect of androgens in our study on body condition, while a detrimental effect would probably lower instead of elevating red eye ring coloration and size. Nevertheless, we analyzed the association between $\mathrm{T}$ levels, color and size of the trait within $\mathrm{T}$ birds only in order to detect whether $\mathrm{T}$ affected the eye ring traits in a dose-dependent manner. For none of the traits we could find any indication that this was the case, nor when tested linearly or quadratic (all $p>0.30$ ).

Eye ring regulation by gonadal hormones

We found that the androgens T and DHT, both binding to the same androgen receptor (Roy et al. 1999) increased eye ring hue, UV-chroma and size both in males and females, while E2 was ineffective in changing size and decreased coloration to some extent. Both androgens increased chroma as well, but only in males. This is the first study showing a positive effect of androgens on color while excluding a role for E2, suggesting that the mechanism regulating bare skin coloration could involve specifically the androgen receptor. However, stronger evidence for a specific role for androgen receptor regulation should be acquired through additional experiments using, e.g., andro- gen blockers or investigating receptor expression at histological level.

Importantly, we did not find any evidence supporting indirect regulation of carotenoid deposition by androgens via their stimulatory effect on circulating levels of lipoproteins. In those treatment groups in which color was enhanced (T and DHT) lipoproteins were not elevated. Although we did not separate the main carotenoid transporter, HDL, from LDL or VLDL, the decoupling of lipoproteins and carotenoid expression is further substantiated by our finding that cholesterol increased only in E2 birds, the only group that did not show an increase in coloration. This indicates that the intensity of the signal is not due to the increase of lipoproteins alone, but to the concurrent activation of cell receptivity for carotenoids, which in turn is receptor dependent (cf., Kiefer et al. 2002 for carotenoids uptake and Rigotti et al. 1997; Rigotti et al. 2003 for selective lipoprotein uptake). This does not support the hypothesis that the cost of displaying carotenoid-based traits is represented by the cost of lipoprotein production (McGraw et al. 2006). Our results are consistent with the hypotheses that the cost of carotenoid-based signals may be the action of $\mathrm{T}$ on the immune system (immunocompetence handicap hypothesis; Folstad and Karter 1992) or on the oxidative stress status (oxidative handicap hypothesis; Alonso-Alvarez et al. 2007). One may, however, argue that some studies showed that administering cholesterol to birds caused an increase in circulating carotenoids (Allen and Wong 1993; McGraw and Parker 2006) and an enhancement of carotenoid coloration (McGraw and Parker 2006). Unfortunately neither of these studies ascertained the level of androgens after cholesterol treatment, as cholesterol is the precursor of testosterone and the up regulation of cholesterol is the first step of the complex steroidogenesis processes involving different kinds of cell and lipoprotein receptors (Tóth et al. 1997; Capponi 2004). Moreover, cholesterol supplementation may improve the bird's condition and stimulate reproductive activity and testosterone production.

Androgen regulation of carotenoid deposition at trait level can be mediated by androgen receptors that in turn regulate the expression of other receptors involved in regulating the selective uptake of carotenoids into the cell, such as the scavenger receptor. Class B scavenger receptor is a cell surface receptor that can recognize the apolipoproteins on the surface of the HDL particle (Rigotti et al. 1997). The loss of function of a class B scavenger receptor is associated with a carotenoid-deficient phenotype in the fruit fly Drosophila (Kiefer et al. 2002). We are not aware of any study on avian scavenger receptors but it seems a quite conservative receptor that can be found both in invertebrates and vertebrates (Rigotti et al. 1997; Kiefer et al. 2002). 
Sex-specific effects of steroids

We found that both males and females increased the hue, UV-chroma and size of the eye ring when treated with androgens, suggesting a similar mechanism in sexual trait regulation for the two sexes. We did not gather evidence that high concentration of androgens were badly tolerated by females, as we did not find any decrease of body condition or color loss after T treatment, as observed in T-treated zebra finch females (McGraw 2006a, b). Moreover, we showed that part of $\mathrm{T}$ administered to the birds was converted to DHT in both sexes, showing that females posses the same physiological competence of males in metabolizing androgens. Since the data on color variables, size and body condition were corrected for the initial values the birds displayed before hormone treatment, the sex difference in size indicate that males are more sensitive to androgens than females, as shown also by higher values of chroma registered in males relative to females treated in the androgen group.

Studies comparing the effect of androgens on color-ornaments in adult male and female birds are scarce (Ketterson et al. 2005; Zysling et al. 2006). To our knowledge, the only study that has considered the effect of androgens on the variation of a fleshy sexual trait in both males and females has been carried out in the moorhen Gallinula chloropus (Eens et al. 2000). Although male moorhens have a larger shield than females, $\mathrm{T}$ manipulations affect shield size and redness of males and females in the same way (Eens et al. 2000). Recently, evidence is accumulating that male sexual ornaments may not only share genetic and endocrinological control mechanisms with that of females as being correlated traits, but that in monogamous species female ornaments are under sexual selection like in the male sex, even when the female ornament is less conspicuous that in the male (Amundsen 2000; Ketterson et al. 2005). The diamond dove is such a monogamous species.

In conclusion, we demonstrated that the eye ring of diamond doves contains high amounts of several carotenoids, mostly metabolized from two carotenoids taken up from the food. We confirmed what was already known for this species (Gray 1970; Voets 1980), that the eye ring is a sexually dimorphic trait, specifically, eye ring size is always larger in males than females independent of hormone treatment, while color dimorphism depends much on the endocrine status of birds. Specifically, color and size of the eye ring are sexually dimorphic in both sexes under the control of androgens but not estrogens, with the size of the ring and to some extent color (chroma) in males being more sensitive to androgens than in females. We found no evidence for the hypothesis that the production of the transporter of carotenoids may be a cost to sexual signaling.

Acknowledgments We are grateful to Riccardo Stradi and Vittorio Bertacche for HPLC analyses, to Bonnie deVries for helping with RIA analyses and to Cheryl Ball for language revision. The study has been funded by the European Union within the 6th Framework Program (EIF Marie Curie Project no. 025369-HormColour, 2006-2008). All experiments were carried out under specific licenses of the Dutch government and the University Ethical Committee for animal experiments.

Open Access This article is distributed under the terms of the Creative Commons Attribution Noncommercial License which permits any noncommercial use, distribution, and reproduction in any medium, provided the original author(s) and source are credited.

\section{Appendix}

Table 4 Original values of transformed hormone data

\begin{tabular}{lccc}
\hline Groups & \multicolumn{2}{l}{ Hormones $\left(\mathrm{pg} \mathrm{mL}^{-1}\right)$} & \\
\cline { 2 - 4 } & DHT & $\mathrm{T}$ & $\mathrm{E} 2$ \\
\hline C females $(n=6)$ & $217.27 \pm 67.95$ & $2,768 \pm 639$ & $2,515.66 \pm 934.92$ \\
C males $(n=6)$ & $280.41 \pm 42.96$ & $3,707 \pm 467$ & $429.71 \pm 290.79$ \\
E females $(n=6)$ & $165.93 \pm 37.63$ & $2,171 \pm 310$ & $3,025.90 \pm 1,053.65$ \\
E males $(n=5)$ & $546.20 \pm 332.72$ & $5,465 \pm 2,487$ & $5,744.61 \pm 2,318.67$ \\
T females $(n=7)$ & $3,076.33 \pm 518.14$ & $20,749 \pm 3,256$ & $412.75 \pm 175.62$ \\
T males $(n=5)$ & $3,339.12 \pm 882.85$ & $22,407 \pm 5,875$ & $153.61 \pm 131.35$ \\
D females $(n=6)$ & $910.97 \pm 313.70$ & $2,324 \pm 563$ & $151.23 \pm 99.55$ \\
D males $(n=6)$ & $1,924.50 \pm 732.4$ & $11,691 \pm 8,168$ & $494.39 \pm 275.14$ \\
\hline
\end{tabular}




\section{References}

Allen PC, Wong HYC (1993) Effect of atherogenic diet on chicken plasma lipids and lipoproteins. Poult Sci 72:1673-1678

Alonso-Alvarez C, Bertrand S, Faivre B, Chastel O, Sorci G (2007) Testosterone and oxidative stress: the oxidation handicap hypothesis. Proc R Soc Lond B 274:819-825

Alonso-Alvarez C, Pérez-Rodríguez L, Mateo R, Chastel O, Viñuela J (2008) The oxidation handicap hypothesis and the carotenoid allocation trade-off. J Evol Biol 21:1789-1797

Alonso-Alvarez C, Pérez-Rodríguez L, Garcia JT, Viñuela J (2009) Testosterone-mediated trade-offs in the old age: a new approach to the immunocompetence handicap and carotenoid-based sexual signalling. Proc R Soc Lond B 276:2093-2101

Amundsen T (2000) Why are female birds ornamented? Trends Ecol Evol 15:149-155

Andersson S, Prager M (2006) Quantifying colors. In: Hill GE, McGraw KJ (eds) Bird coloration, mechanisms and measurements, volume 1. Harvard University Press, Cambridge, MA, pp 41-89

Andersson S, Pryke SR, Ornborg J (2002) Multiple receivers, multiple ornaments, and a trade-off between agonistic and epigamic signaling in a widowbird. Am Nat 160:683-691

Ando S, Hatano M (1988) Isolation of apolipoproteins from carotenoid-carrying lipoprotein in the serum of chum salmon, Oncorhynchus keta. J Lipid Res 29:1264-1271

Blas J, Perez-Rodriguez L, Bortolotti GR, Vinuela J, Marchant TA (2006) Testosterone increases bioavailability of carotenoids: insights into the honesty of sexual signaling. Proc Natl Acad Sci USA 103:18633-18637

Capponi AM (2004) The control by angiotensin II of cholesterol supply for aldosterone biosynthesis. Mol Cell Endocrinol 217:113-118

Casagrande S, Csermely D, Pini E, Bertacche V, Tagliavini J (2006) Skin carotenoid concentration correlates with male hunting skill and territory quality in the kestrel (Falco tinnunculus). J Avian Biol 37:190-196

Chapman M (1980) Animal lipoproteins: chemistry, structure, and comparative aspects. J Lipid Res 21:789-853

Chastel O, Lacroix A, Weimerskirch H, Gabrielsen G-W (2005) Modulation of prolactin but not corticosterone responses to stress in relation to parental effort in a long-lived bird. Horm Behav 47:459-466

Costantini D, Moller AP (2008) Carotenoids are minor antioxidants for birds. Funct Ecol 22:367-370

Costantini D, Fanfani A, Dell'Omo G (2007) Carotenoid availability does not limit the capability of nestling kestrels (Falco tinnunculus) to cope with oxidative stress. J Exp Biol 210:1238-1244

Costantini D, Bertacche V, Pastura B, Turk A (2009) Dehydrolutein: a metabolically derived carotenoid never observed in raptors. Curr Zool 55:238-242

Czeczuga B (1978) Carotenoids in the skin of certain species of birds. Comp Biochem Physiol B 62:107-109

Darwin C (1871) The descent of man and selection in relation to sex. John Murray, London

Dashti N, Kelley J, Thayer R, Ontko J (1983) Concurrent inductions of avian hepatic lipogenesis, plasma lipids, and plasma apolipoprotein B by estrogen. J Lipid Res 24:368-380

Eens M, van Duyse EV, Berghman L, Pinxten R (2000) Shield characteristics are testosterone-dependent in both male and female moorhens. Horm Behav 37:126-134

Faivre B, Grégoire A, Préault M, Cézilly F, Sorci S (2003) Immune activation rapidly mirrored in a secondary sexual trait. Science 300:103

Folstad I, Karter AJ (1992) Parasites, bright males, and the immunocompetence handicap. Am Nat 139:603-622
Fridolfsson A-K, Ellegren H (1999) A simple and universal method for molecular sexing of non-ratite birds. J Avian Biol 30:116-121

Gesa AI, Hoeller U, Schierle J, Neuringer M, Johnson EJ, Schalch W (2008) Metabolism of lutein and zeaxanthin in rhesus monkeys: Identification of $\left(3 R, 6^{\prime} R\right)$ - and $\left(3 R, 6^{\prime} S\right)-3^{\prime}$-dehydro-lutein as common metabolites and comparison to humans. Comp Biochem Physiol B: Biochem Mol Biol 151:70-78

Gingras S, Turgeon C, Brochu N, Soucy P, Labrie F, Simard J (2003) Characterization and modulation of sex steroid metabolizing activity in normal human keratinocytes in primary culture and HaCaT cells. J Steroid Biochem Mol Biol 9(87):167-179

Gray M (1970) The fallow dove. International Dove Society Newsletter. http://www.internationaldovesociety.com/articles/thediamonddove.htm

Groothuis TGG, Dütmann H (2008) Testosterone increased bloodbased red bill colouration in the common shelduck. In: Poster and abstract of the International Symposium on Avian Endocrinology 2008, Leuven

Grossman CJ (1985) Interactions between the gonadal steroids and the immune system. Science 227:257-261

Hardesty M (1931) The structural basis for the response of the comb of the brown leghorn fowl to the sex hormones. Am J Anat 47:277323

Hart NS, Vorobyev M (2005) Modelling oil droplet absorption spectra and spectral sensitivities of bird cone photoreceptors. J Comp Physiol A 191:381-392

Johnsen A, Delhey K, Andersson S, Kempenaers B (2003) Plumage colour in nestling blue tits: sexual dichromatism, condition dependence and genetic effects. Proc R Soc Lond B 270:12631270

Ketterson ED, Nolan V Jr, Wolf L, Ziengenfus C, Dufty AM, Ball GF, Johnsen TS (1991) Testosterone and avian life-histories: the effects of experimentally elevated testosterone on corticosterone and body mass in dark-eyed juncos. Horm Behav 25:489-503

Ketterson ED, Nolan V Jr, Sandell M (2005) Testosterone in females: mediator of adaptive traits, constraint on sexual dimorphism, or both? Am Nat 166:S85-S98

Kiefer C, Sumser E, Wernet MF, von Lintig J (2002) A class B scavenger receptor mediates the cellular uptake of carotenoids in Drosophila. Proc Natl Acad Sci USA 99:10581-10586

Kristiansen KO, Bustnes JO, Folstad I, Helberg M (2006) Carotenoid coloration in great black-backed gull Larus marinus reflects individual quality. J Avian Biol 37:6-12

Kudzma DJ, Hegsted PM, Stoll RE (1973) The chick as a laboratory model for the study of estrogen-induced hyperlipidemia. Metabolism 22:423-434

Lee EH, Faulhaber D, Hanson KM, Ding W, Peters S, Kodali S, Granstein RD (2004) Dietary lutein reduces ultraviolet radiation-induced inflammation and immunosuppression. J Invest Dermatol 122:510-517

Lessels CM, Boag PT (1987) Unrepeatable repeatabilities: a common mistake. Auk 104:116-121

Levin ER (2005) Integration of the extranuclear and nuclear actions of estrogen. Mol Endocrin 19:1951-1959

Luskey KL, Brown MS, Goldstein JL (1974) Stimulation of the synthesis of very low density lipoproteins in rooster liver by estradiol. J Biol Chem 249:5939-5947

Martínez-Padilla J, Mougeot F, Pérez-Rodríguez L, Bortolotti GR (2007) Nematode parasites reduce carotenoid-based signalling in male red grouse. Biol Lett 3:161-164

McGlothlin JW, Ketterson ED (2008) Hormone-mediated suites as adaptations and evolutionary constraints. Phil Trans R Soc B 363:1611-1620

McGraw KJ (2006a) Mechanisms of carotenoid-based coloration. In: Hill GE, McGraw KJ (eds) Bird coloration, mechanisms and 
measurements, volume 1. Harvard University Press, Cambridge, MA, pp 177-242

McGraw KJ (2006b) Sex steroid dependence of carotenoid-based coloration in female zebra finches. Physiol Behav 88:347-352

McGraw KJ, Ardia DR (2003) Carotenoids, immunocompetence, and the information content of sexual colors: an experimental test. Am Nat 162:704-712

McGraw KJ, Ardia DR (2007) Do carotenoids buffer testosterone-induced immunosuppression? An experimental test in a colourful songbird. Biol Lett 3:375-378

McGraw KJ, Parker RS (2006) A novel lipoprotein-mediated mechanism controlling sexual attractiveness in a colorful songbird. Physiol Behav 87:103-108

McGraw KJ, Correa SM, Adkins-Regan E (2006) Testosterone upregulates lipoprotein status to control sexual attractiveness in a colorful songbird. Behav Ecol Sociobiol 60:117-122

Møller AP, Biard C, Blount JD, Houston DC, Ninni P, Surai PF (2000) Carotenoid-dependent signals: indicators of foraging efficiency, immunocompetence or detoxification ability? Avian Poult Biol Rev 11:137-159

Montgomerie R (2006) Analyzing colors. In: Hill GE, McGraw KJ (eds) Bird coloration, mechanisms and measurements, volume 1. Harvard University Press, Cambridge, MA, pp 90-147

Mougeot F (2008) Ornamental comb colour predicts T-cell-mediated immunity in male red grouse Lagopus lagopus scoticus. Naturwissenschaften 95:125-132

Mougeot F, Redpath SM, Leckie F (2005) Ultra-violet reflectance of male and female red grouse, Lagopus lagopus scoticus, sexual ornaments reflect nematode parasite intensity. J Avian Biol 36:203-209

Mougeot F, Perez-Rodriguez L, Martinez-Padilla J, Leckie F, Redpath SM (2007) Parasites, testosterone and honest carotenoid-based signalling of health. Funct Ecol 21:886-898

Mougeot F, Perez-Rodriguez L, Sumozas N, Terraube J (2009) Parasites, condition, immune responsiveness and carotenoid-based ornamentation in male red-legged partridge Alectoris rufa. J Avian Biol 40:67-74

Muehlenbein MP, Bribiescas RG (2005) Testosterone-mediated immune functions and male life histories. Am J Hum Biol 17:527558

Olsen NJ, Kovacs WJ (1996) Gonadal steroids and immunity. Endocr Rev 17:369-384

Olson VA, Owens IPF (1998) Costly sexual signals: are carotenoids rare, risky or required? Trends Ecol Evol 13:510-514

Parker R (1996) Absorption, metabolism, and transport of carotenoids. FASEB J 10:542-551

Pérez-Rodríguez L (2009) Carotenoids in evolutionary ecology: reevaluating the antioxidant role. BioEssays 31:1116-1126

Perez-Rodriguez L, Vinuela J (2008) Carotenoid-based bill and eye ring coloration as honest signals of condition : an experimental test in the red-legged partridge (Alectoris rufa). Naturwissenschaften 95:821-830

Perez-Rodriguez L, Mougeot F, Alonso-Alvarez C, Blas J, Viñuela J, Bortolotti GR (2008) Cell-mediated immune activation rapidly decreases plasma carotenoids but does not affect oxidative stress in red-legged partridges (Alectoris rufa). J Exp Biol 211:2155-2161

Peters A, Delhey K, Johnsen A, Kempenaers B (2007) The conditiondependent development of carotenoid-based and structural plumage in nestling blue tits: males and females differ. Am Nat 169:S122-S136

Pintea A, Diehl HA, Momeu C, Aberle L, Socaciu C (2005) Incorporation of carotenoid esters into liposomes. Biophys Chem 118:7-14

Pirog EC, Collins DC (1999) Metabolism of dihydrotestosterone in human liver: importance of 3\{alpha\}- and 3 beta\}hydroxysteroid dehydrogenase. J Clin Endocrinol Metab 84:3217-3221
Rigotti A, Trigatti BL, Penman M, Rayburn H, Herz J, Krieger M (1997) A targeted mutation in the murine gene encoding the high density lipoprotein (HDL) receptor scavenger receptor class B type I reveals its key role in HDL metabolism. Proc Natl Acad Sci USA 94:12610-12615

Rigotti A, Miettinen HE, Krieger M (2003) The role of the high-density lipoprotein receptor SR-BI in the lipid metabolism of endocrine and other tissues. Endocr Rev 24:357-387

Roberts ML, Buchanan KL, Evans MR (2004) Testing the immunocompetence handicap hypothesis: a review of the evidence. Anim Behav 68:227-239

Roselli CE, Resko JA (1993) Aromatase activity in the rat brain: hormonal regulation and sex differences. J Steroid Biochem Mol Biol 44:499-508

Roy AK, Lavrovsky Y, Song CS, Chen S, Jung MH, Velu NK, Bi BY, Chatterjee B (1999) Regulation of androgen action. Vitam Horm 55:309-352

Roya AK, Lavrovskya Y, Songa CS, Chena S, Junga MH, Velua NK, Bia BY et al (1998) Regulation of androgen action. Vitam Horm 55:309-332

Saino N, Bertacche V, Ferrari RP, Martinelli R, Møller AP (2002) Carotenoid concentration in barn swallow eggs is influenced by laying order, maternal infection and paternal ornamentation. Proc R Soc B 269:1729-1733

Schaeffer JL, Tyczkowski JK, Hamilton PB (1988) Depletion of oxycarotenoid pigments in chickens and the failure of aflatoxin to alter it. Poult Sci 67:1080-1088

Schiedt K, Bischof S, Glintz E (1995) Example 6: egg yolk. In: Britton G, Liaaen-Jensen S, Pfander H (eds) Carotenoids, vol IA. Birkhäuser, Basel, pp 253-260

Schleucher E, Prinzinger R, Withers PC (1991) Life in extreme environments: investigations on the ecophysiology of a desert bird, the Australian diamond dove (Geopelia cuneata). Oecologia 88:72-76

Soma KK, Tramontin AD, Wingfield JC (2000) Oestrogen regulates male aggression in the non-breeding season. Proc R Soc Lond B 267:1089-1096

Stradi R, Celentano G, Nava D (1995) Separation and identification of carotenoids in bird's plumage by high-performance liquid chromatography-diode-array detection. J Chromatgr B 670:337-348

Subagio A, Wakaki H, Morita N (1999) Stability of lutein and its myristate esters. Biosci Biotechnol Biochem 63:1784-1786

Tóth IE, Szabó D, Bruckner GG (1997) Lipoproteins, lipid droplets, lysosomes, and adrenocortical steroid hormone synthesis: morphological studies. Microsc Res Tech 36:480-492

Tramontin AD, Wingfield JC, Brenowitz EA (2003) Androgens and estrogens induce seasonal-like growth of song nuclei in the adult songbird brain. J Neurobiol 57:130-140

Tyczkowski JK, Hamilton PB (1986) Absorption, transport, and deposition in chickens of lutein diester, a carotenoid extracted from marigold (Tagetes erecta) petals. Poult Sci 65:1526-1531

Vanhoutteghem A, Londero T, Ghinea N, Djian P (2004) Serial cultivation of chicken keratinocytes, a composite cell type that accumulates lipids and synthesizes a novel B-keratin. Differentiation 72:123-137

Voets P (1980) The diamond dove. International Dove Society Newsletter. http://www.internationaldovesociety.com/articles/thediamonddove.htm

Wingfield JC, Matt KS, Farner DS (1984) Physiologic properties of steroid-hormone binding proteins in avian blood. Gen Comp Endocrinol 53:281-292

Zahavi A (1975) Mate selection—a selection for a handicap. J Theor Biol 53:205-214

Zysling DA, Greives TJ, Breuner CW, Casto JM, Demas GE, Ketterson ED (2006) Behavioral and physiological responses to experimentally elevated testosterone in female dark-eyed juncos (Junco hyemalis carolinensis). Horm Behav 50:200-207 